\title{
Los alminares almohades de La Axarquía
}

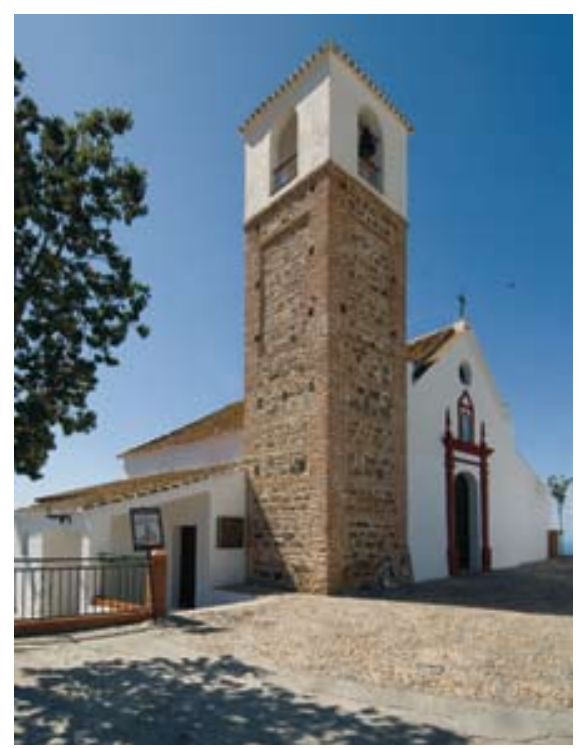

Corumbela. Foto: Juan Carlos Cazalla, IAPH

\section{Los alminares de La Axarquía, de inspiración merini y construidos en los siglos XIII-XIV, son únicos en toda Andalucía}

Los Almohades (literalmente, "los partidarios de la unicidad") surgieron como un movimiento religioso reformista, que aglutinó a diversas tribus montañesas del atlas norteafricano. Tras la muerte de su fundador emprendieron una rápida expansión y en el 1147 ocuparon Marrakech y Sevilla, a las que convirtieron en capitales de su imperio. Su dominio en la Peninsula Ibérica acabaria en la decisiva batalla de las Navas de Tolosa en 1212.

En La Axarquía, durante el siglo XII se había producido un despoblamiento generalizado de las poblaciones mozárabes autóctonas de las sierras de Bentomiz y Tejeda-Almijara, debido a que fueron expulsados o trasladados. Tal situación fue aprovechada para introducirse grupos beréberes norteafricanos, como fueron los Masmudas, llegados con los ejércitos almohades, que se establecieron desde Canillas de Aceituno hasta Nerja. También en otras áreas de La Axarquia se instalaron otros grupos como los Gomeres que tuvieron una cierta implantación en la ciudad de Vélez.

La influencia de estos grupos durante los siglos XIII y

$\mathrm{XV}$ fue importante en esta zona cuya huella se puede rastrear en los singulares alminares, hoy dia torrescampanarios, de las localidades de Vélez-Málaga, Daimalos, Corumbela, Árchez y Salares, lo mismo que Arenas que fue destruido. Estos alminares son típicos minaretes de los siglos XIII-XIV, de inspiración merini, únicos en toda La Axarquia y Andalucia. La ascendiente africana es determinante, donde la práctica totalidad de sus fachadas se decoran, dejando libres las esquinas, según modelos similares de los alminares meriníes de Tremencén, edificado en 1231, y de Túnez, de 1353. Son de proporciones armoniosas, su altura es cuatro veces la de uno de sus lados, y su plan decorativo se desarrolla a partir del segundo cuerpo, con rectángulos rehundidos en los que suelen aparecer los llamados paños de sebka, cintas horizontes de azulejos, franja de arcos apuntados, etc.

La mezquita ocupa el lugar central en la arquitectura islámica y representa el símbolo de la fe a la que se sirve. Este elemento simbólico fue comprendido por los musulmanes en una etapa temprana, y desempeñó un papel importante en la creación de adecuados signos visibles para el edificio: el alminar, la quibla y el Mihrab. Desde lo alto del alminar (torre de la mezquita) el muecin llama a los musulmanes a la oración, es el signo más prominente de la mezquita. Los alminares españoles y norteafricanos, que comparten la torre cuadrada tradicional de los sirios, están decorados con paneles de motivos ornamentales dispuestos en torno a ventanas geminadas.

Por las fuentes castellanas sabemos que en la zona meridional de la ciudad medieval de Vélez existía un amplio barrio conocido como el Arrabal de Los Gomeres, donde se habia instalado este grupo beréber norteafricano. Este sector urbano quedaba com-

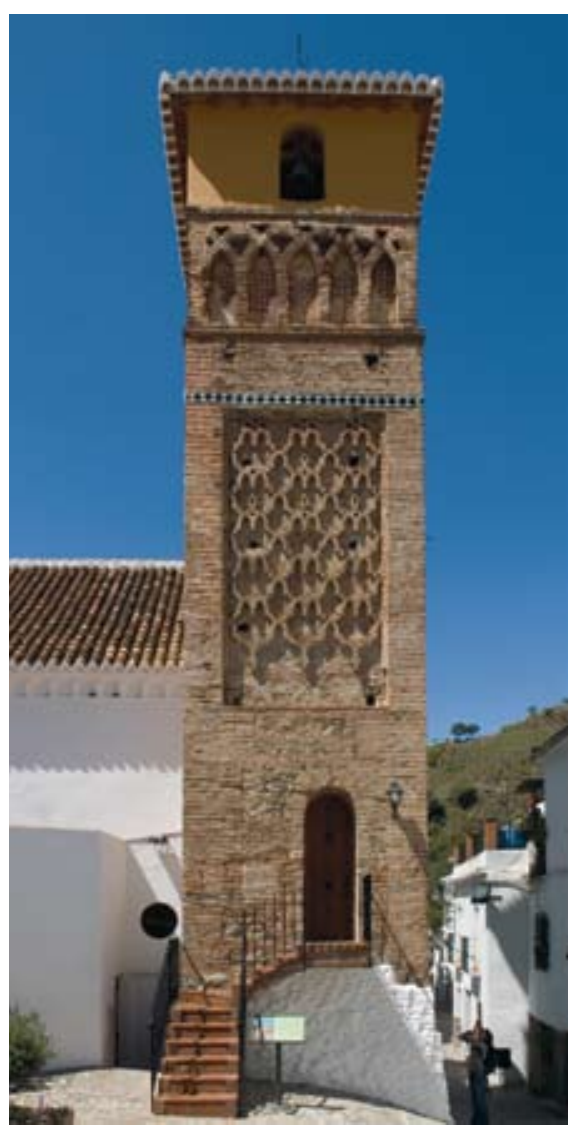

Árchez. Foto: Juan Carlos Cazalla, IAPH prendido por los actuales barrios de San Francisco y La Gloria, y estaba vinculado especialmente con distintos espacios de carácter cultual, caso de un ribat (que se ubicaba donde se encuentra la actual Ermita de Ntra. Sra. de Los Remedios) y el cementerio de la ciudad musulmana que tenía próximo una mezquita (que se corresponderia con la iglesia del convento franciscano de Santiago), y otras mezquitas menores.

El cementerio musulmán se extendia desde el convento franciscano hasta las plazas de la Concepción y Capuchinos del actual casco urbano veleño. La mezquita más importante de este barrio, que estaba próxima a la necrópolis, se encontraba en la actual iglesia del Convento de Santiago, de la que ha quedado como testimonio su antiguo alminar que fue convertido en torre-campanario y que se encuentra a los pies de iglesia. En los recientes trabajos de rehabilitación del convento se han descubierto diferentes sectores del alminar con la típica decoración de paños de sebka, destacando una amplia zona de la cara norte y pequeños segmentos en los lados sur y oeste, que estaban muy dañados por las obras del convento en el siglo XVI. Al norte se pudo constatar la presencia de la parte media y alta de un gran rectángulo rehundido, decorado con paño de sebka que se realiza por medio de ladrillos recortados, que forman rombos mixtilineos y rematados en su parte superior por piezas circulares, conservándose restos de pintura mural de color rojo almagra con temas vegetales. Ha sido una novedad descubrir que los huecos de las piezas circulares se rellenaban con azulejos de color verde y negro, como también ha sido una sorpresa documentar que todo el rectángulo quedaba delimitado al exterior por una línea de piezas rectangulares de azulejos de color verde.

También ha sido descubierto con las obras de rehabilitación el acceso al alminar, que se encontraba en su lado oeste. Su interior cuenta con un machón central en torno al cual se desarrolla una escalera.

Este alminar guarda estrecha relación con los de Árchez y Salares, pero habrá que esperar a la definitiva rehabilitación del campanario para poder descubrir más zonas de este antiguo alminar y tener un mejor conocimiento del mismo. Para poder contemplar los paños de sebka, que se encuentran en un pequeño patio interior de la primera planta, deberán solicitar a los franciscanos del convento permiso para su acceso.

Inmersos en los dominios de la Sierra de Bentomiz, al noroeste de Vélez, encontramos Daimalos donde haIlaremos un magnífico alminar, convertido en el siglo $\mathrm{XVI}$ en torre-campanario de su Iglesia Ntra. Sra. de la Concepción, y que está considerado como el más arcaico de todos. Consta de cuatro cuerpos, si bien el último es añadido como cuerpo de campanas. Su primer cuerpo es el más ancho y alto, carece de decoración y tiene unos pequeños huecos para permitir una mínima iluminación. El segundo cuerpo, que está 


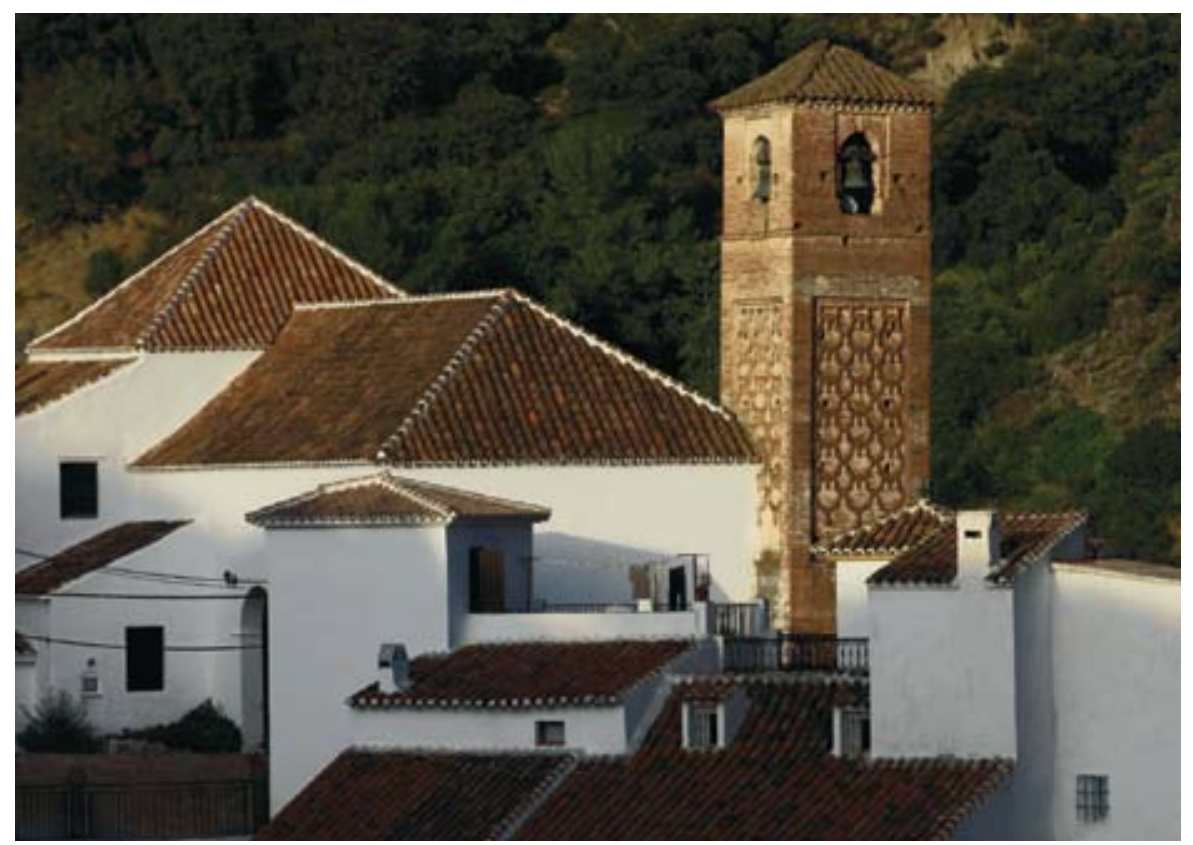

Salares. Foto: Miguel Ángel Blanco de la Rubia

separado del anterior por una linea de imposta, es el único que presenta decoración en su fachada mediante cuatro arcos ciegos apuntados. El tercer cuerpo, igualmente separado por otra línea de imposta, es liso y carece de ornato. En el interior encontramos una angosta escalera, que se dispone de forma radial sobre un machón central macizo, que solo permite el paso a una persona.

A varios kilómetros de Daimalos se encuentra Corumbela, cuya iglesia esta consagrada a la advocación de San Pedro y que se encuentra a la salida del pueblo en dirección a Árchez. En el exterior, en el lateral derecho del templo, se alza el alminar realizado en mampostería de gruesas piedras alternadas por hiladas de ladrillo, con estructura de prisma rectangular. Este se relaciona con el de Árchez, aunque es de menor importancia. Ha llegado hasta nosotros muy mutilado debido a una notable transformación externa al adaptarse como torre-campanario. En el cuerpo central aparece, en cada lado del alminar, un rectángulo rehundido que debió albergar los paños de sebka con sus rombos mixtilíneos, no conservándose ninguno. El siguiente cuerpo queda separado por una línea de imposta, modificado para la realización del campanario, presenta una corta franja horizontal donde se destaca la presencia de una serie de arcos apuntados, que se cegaron en época cristiana, que también pueden observarse en su lado interno. En el interior de la torre encontramos las escaleras alrededor de un machón central con bóvedas de medio cañón escalonadas, ubicándose el ladrillo de modo radial y horizontalmente, aunque se encuentran tramos muy mal conservados, incluso se pueden encontrar vigas y cañas con yeso.

A unos $4 \mathrm{~km}$ al noroeste de Corumbela encontramos el pueblo de Árchez, donde descubriremos un hermoso alminar muy bien conservado, que se localiza en la cabecera de la Iglesia de Ntra. Sra. de la Encarnación al que se accede desde el exterior, desde una pequeña puerta que está a unos 1,7 m del suelo, quedando por encima del original. Tiene unas proporciones bastante armónicas, con una altura de $15 \mathrm{~m}$ y 3,64 m de lado. En el interior se dispone un cuadrado macizo o machón de 1,07 m de lado en torno al cual se desarrolla una escalera cubierta con bóveda escalonada de medio cañón.

Se realiza en mamposteria y ladrillo, y se compone de cuatro cuerpos. En el segundo de ellos, que es el más amplio, se decoran sus cuatro lados con rectángulos rehundidos adornos (¿adornados?) con paños de sebka, por medio de ladrillos recortados que forman rombos mixtilíneos, entre los que se conservan restos de pinturas originales de color rojo almagra. Comenzaba la parte inferior de los paños con unas pequeñas columnas o arcos, hoy dia desaparecidas, mientras que su parte superior queda rematada por piezas circulares. Por encima de los rectángulos se crea una franja horizontal de azulejos policromos en blanco con rombos azules que recorre todo los lados de la torre. El tercer cuerpo está caracterizado por una franja horizontal de cinco arcos ciegos de herradura apuntados entrelazados, donde también se conservan

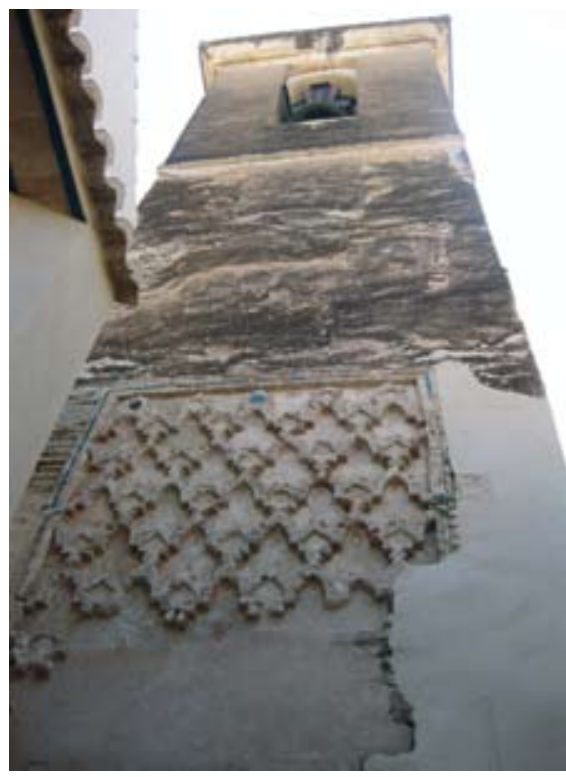

Vélez-Málaga. Convento de San Francisco. Foto: Emilio Martín Córdoba

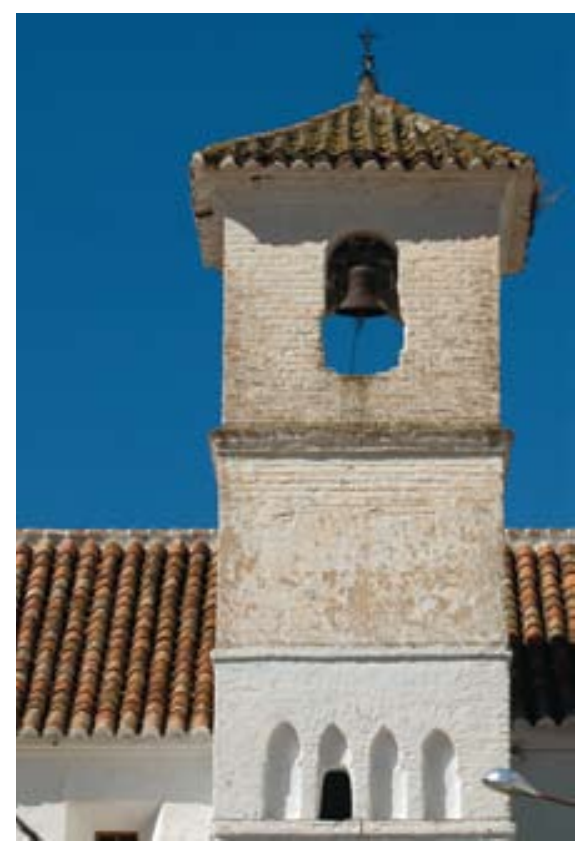

Daimalos. Foto: Juan Carlos Cazalla, IAPH

restos de pintura original relacionados con rombos, cuadrados y dameros. El último cuerpo, donde estaba la terraza del alminar, fue eliminado para albergar las campanas y cubierto con tejado a cuatro aguas.

La localidad de Salares, que es uno de los pocos pueblos de La Axarquia que ha conservado parte de su caserio tradicional, presenta un alminar que domina el paisaje urbano, localizado en el lado derecho de la actual Iglesia de Santa Ana, definido por una estructura de prisma rectangular. Mantiene una estrecha relación con el de Árchez, aunque con unas dimensiones algo menores, pues su altura es de unos $12 \mathrm{~m}$ y su lado es de 3,5m. A igual que éste, su acceso se realiza desde el exterior con una entrada que queda más elevada que la original. Al igual que los anteriores, el interior cuenta con un pilar macizo central, de unos 0,9 $\mathrm{m}$ de ancho, sobre el que se dispone una escalera con bóveda de medio cañón escalonada con aristas en los extremos.

Está realizado en ladrillo y mampostería, componiéndose de tres cuerpos, el primero no presenta ningún tipo de decoración, si bien queda rematado por un rectángulo horizontal de azulejos donde se disponen dos filas de rombos azules sobre fondo blanco. El segundo cuerpo, más amplio en longitud, se compone de rectángulos rehundidos con paños de sebka en los cuatro lados, compuestos por rombos mixtilíneos realizados por ladrillos recortados, que dejan las esquinas libres sin decoración. En la parte inferior de los rombos mixtilíneos han desaparecido unas pequeñas columnas, igual que ocurre en Árchez, y no ha quedado ningún rastro de pintura mural. El último cuerpo, añadido en época cristiana para albergar las campanas, comienza a partir de una imposta y queda cubierto por un tejado a cuatro aguas. Adentrándonos en el patio oeste de la iglesia nos encontraremos con los restos de pilares y arcos apuntados, que se corresponden con la antigua mezquita.

Emilio Martín Córdoba

Arqueólogo 